\title{
Editorial
}

Plínio Prado*

Manoel Tosta Berlinck nos deixou no dia 21 de junho último, aos 79 anos.

Sociólogo, psicanalista, editor da Revista Latinoamericana de Psicopatologia Fundamental, o seu desaparecimento suscitou inúmeros necrológios e homenagens, a começar pelos dos colegas e amigos da Associação Universitária de Pesquisa em Psicopatologia Fundamental (AUPPF), assim como os das instituições nas quais ele atuou (Unicamp, PUC-SP, FGV...). Esses testemunhos encontram-se disponiveis na Internet.

Face à sua partida irreparável e a tristeza profunda na qual ela nos deixa, a presente edição de sua Revista Latinoamericana de Psicopatologia Fundamental não poderia deixar de ser, em sua homenagem, uma edição especial.

*Université de Paris VIII (Paris, França). 


\section{Ao Manoel Berlinck que eu conheci}

Escrever aqui, sobre um amigo raro que acabou de morrer há alguns meses, é um imenso desafio. Difícil, doloroso e perigoso.

Como ele - o amigo que se foi — julgaria o que vai ser dito aqui, como ele o julgará ? Pois eu ouço a voz dele, ele está aqui, escutando tudo atentamente.

A morte, o incomensurável absoluto, é isso sobre o que a linguagem não pode falar. É o que cada um pressente, cada vez que experimenta o quanto são vãs, se não ridículas, as palavras de condolência pela morte de um ente querido.

Três semanas antes de morrer, Manoel me escrevia: o "Congresso de João Pessoa... será, certamente, um evento marcante, principalmente devido ao momento vivido. Precisamos, por isso, aproveitar a oportunidade para tratar da questão da qualidade, muito carente no Brasil". Ele sublinhava, em seguida, "a grande incompetência e falta de qualidade" de nossos políticos.

Isso foi no dia $1^{\circ}$ de junho último. Na madrugada do dia 21 , morreu.

O Congresso que ele planejou e desejou, o último que preparou, aconteceu em João Pessoa entre os dias 7 e 11 de setembro. $\mathrm{O}$ evento marcante foi a ausência dele.

A primeira presença de Manoel Berlinck está associada para mim, como para muitos dentre nós, à cena da sala de aula. Eu o encontrei como professor de Sociologia no Instituto de Filosofia e Ciências Humanas (IFCH) da Unicamp, num curso sobre Durkheim, "As regras do método sociológico". Já se tratava da questão do método, que acompanhará, insistentemente, toda a vida de Manoel: discurso do método, caminhos da terapia psicanalítica, qualidade no método clínico.

A amizade tem pelo menos este ponto em comum com o amor: ela ignora em princípio a idade, a experiência, a hierarquia, a classe social, 


\section{EDITORIAL}

o sexo. Manoel foi, claro, professor, pai, interlocutor, colega, mas o termo que para mim determina e dá o tom geral é: amigo.

Nós nos perdemos de vista durante duas décadas, após a minha mudança para a França. Reencontramo-nos no início dos anos 2000, através da correspondência eletrônica. Ele tinha efetuado a sua virada da sociologia para a psicanálise e tinha mudado de vida. Do meu lado eu havia paralelamente criado um seminário, entre Belfort e Paris, consagrado à leitura da obra de Freud.

Quando em 2008 nos revimos em São Paulo, na Livraria Pulsional, ele me convidou para dar uma palestra no Colóquio Internacional de 2009, com German Berrios e alguns outros, que ele estava organizando com Ana Cecília Magtaz na Fundação Álvares Penteado. Tema: o método clínico.

No Congresso internacional de Curitiba de 2010, o tema escolhido foi "O amor e seus transtornos". Manoel havia me convidado para fazer a palestra de abertura e dar um "minicurso". Eu lhe propus falar sobre "a arte de viver à beira do abismo". Os detalhes da argumentação não vêm ao caso aqui. Mas para que se possa compreender bem o que se segue, e a reação de Manoel, convém lembrar ao menos o que tinha me levado a fazer-lhe esta proposição.

A "vida à beira do abismo" é, em primeiro lugar, o leitmotiv inerente ao amor absoluto, o amor-paixão, segundo a grande tradição do romantismo europeu. Em seguida, esse motivo permitiria, no caso, uma articulação importante com o tema inaugural, socrático, da "técnica" ou "arte da existência"; tema que Michel Foucault, após outros, havia reativado nos últimos anos de sua vida, e onde vêm se articular, por sua vez, a cura sui antiga e a talking cure moderna e, portanto, à psicopatologia psicanalítica. Enfim, mas não por último, essa articulação entre romantismo e filosofia serviria de introdução para a reflexão de Freud sobre a escolha do amor como "técnica da arte de viver", ou ainda, como ele dizia, "técnica de realização do princípio de prazer".

É aqui que poderíamos então dar a esse motivo condutor uma formulação freudiana. Freud observa no Mal-estar na civilização que não há "técnica de arte de viver" mais "sublime" do que a que consiste em procurar amar e ser amado. Porque então, pergunta ele, todo mundo não elege esse projeto e essa "técnica" como prioridade absoluta para se realizar na vida (acima de carreira, dinheiro, poder, sucesso)? A resposta salta aos olhos: porque não há, em contrapartida, infortúnio maior do que o de perder o seu objeto de amor, o de ser abandonado por quem amamos. Sem falar, evidentemente, do fato de que amor não se encomenda (como mostram Kant e Beckett). Ele chega sem avisar e desaparece sem prevenir. Como o outro 
me escapa por definição, por ser justamente outro, segue-se daí que amar é viver à beira do abismo. (E porque visavam antes a ataraxia, os filósofos da Antiguidade condenavam, enquanto therapeutai, a paixão amorosa. $\mathrm{O}$ que Freud não deixou de anotar, aprovando.)

Manoel escuta tudo atentamente, sério, interessado. Ele buscaria em seguida articular o motivo da "beira do abismo" com o tema central do método, recurso por excelência, segundo ele, para se lidar com o abissal.

Esse tema tinha ainda um outro interesse, ao qual Manoel era igualmente sensível: a surpreendente convergência entre o leitmotiv do romantismo europeu e a música popular brasileira. Não é difícil demonstrar, com efeito, que o motivo condutor o mais insistente da MPB pode ser condensado em uma frase típica do romantismo: "viver é amar e sofrer". De "Linda flor" em 1928 ("Ai ioiô, eu nasci pra sofrer...") a todo o Vinícius de Moraes, e para além dele. De sorte que esse tema permitiria também realizar um desejo longamente acalentado por Manoel: o de reconciliar o erudito e o popular, a cultura intelectual e a cultura do povo, a qualidade elaborada e o instintivo, a poesia e a canção, a universidade e a rua.

Vinícius resta aqui um modelo, ao mesmo tempo cultivado e popular, em 376 matéria de viver e amar à beira do abismo. A sua poesia é indissociavelmente um projeto ético, uma introdução ao viver, cuja lógica é irrepreensível: se "viver sem amar, não é viver", e se amar é viver à beira do abismo, segue-se que viver é viver à beira do abismo.

Manoel conheceu Vinícius. Eles beberam juntos, trocaram confidências. Não apenas a sua discoteca, mas a sua biblioteca também, assim como as publicações da editora Escuta, testemunham o seu interesse por Vinícius e pela música popular brasileira. Eu arriscaria dizer que, além de sociólogo, psicanalista e um admirável e incansável animador cultural (no melhor sentido do termo: o da cultura do estudo e da pesquisa), Manoel foi também, até certo ponto, viniciano. (Até certo ponto: pois chega uma hora em que o poeta boêmio e o clínico universitário, metódico, necessariamente se separam.)

Manoel adotou literalmente o tema da "arte de viver à beira do abismo". Ele fez da sua expressão um conceito geral, uma espécie de ideia reguladora, que utilizava em diversas ocasiões, inclusive nos trabalhos teóricos.

É assim que num estudo interessante de 2012, sobre o "Método científico nos primórdios da Universidade", podemos ler, a propósito da relação mestre e aluno precisamente: "Quer queira, quer não, um aluno se forma, ou seja, adquire uma forma e se desliga do mestre encaminhando-se para o 


\section{EDITORIAL}

mundo, a realidade. A formatura é o rito de passagem necessário para que aluno e mestre deixem de sê-lo. O rito declara que está formado, ou seja, o aluno é considerado capaz de enfrentar a beira do abismo onde o humano se encontra em sua mais completa solidão, quando deixa de ser infantil".

A formação, a competência, tudo o que Manoel esperava do método, são definidas pela capacidade de lidar com "a beira do abismo": "Diante do abismo enigmático e surpreendente, o estudante lê, observa, analisa, experimenta e pensa. Cada uma dessas atividades é definida por um método, ou seja, por um caminho..." "As falhas na formação não permitem a competente existência para se viver com autonomia na realidade, ou seja, para se viver criativamente à beira do abismo".

Mas a expressão havia se tornado também uma fórmula habitual em suas mensagens. Manoel começava frequentemente assim os seus e-mails: "Querido Plínio, Como vai a vida à beira do abismo?" (dia 21 de junho de 2011). A expressão se tornara pouco a pouco uma senha, um código secreto de reconhecimento entre nós, nos confirmando reciprocamente, nosso shibōleth.

Já em 2010 ele me escrevia, no dia 6 de novembro: "Querido Plínio, Como vai a vida à beira do abismo? Por aqui vamos nos equlibrando na corda bamba. Depois de uma campanha eleitoral pífia, onde os candidatos pareciam títeres de marqueteiros, temos uma dama presidente. Espero que não se revele uma dama de ferro. Prefiro uma dama de copas... Um abraço afetuoso, Manoel”.

Lá por meados de 2013, precisamente no dia 21 de junho, ele me fazia uma descrição, pasmada e preocupada, das passeatas e manifestações que ocorriam no país: "Querido Plínio, Apesar da inflamação geral e irrestrita, vamos trabalhando no Congresso. Seu editorial na Revista Latinoamericana de Psicopatologia Fundamental já começa a repercutir ... O que verdadeiramente nos ocupa, no momento, são as manifestações possibilitadas pela rede social. Trata-se de um fenômeno novo, que nos deixa atônitos e com muitas questões. Parece que o lema, agora, é ‘o povo desunido jamais será vencido'. As reclamações, reivindicações e protestos são os mais variados. Desde as tarifas de transporte público até a 'cura gay'... Essa diversidade, a capacidade impressionante de mobilização e o entusiasmo dos manifestantes é o que mais impressiona. Os políticos estão acuados e com medo. Enfim, é 'o Brasil em chamas'."

Ele se admira em particular com a grande disposição dos jovens, e evoca o entusiasmo de seus enteados, "animados, radiantes e cheios de vida".

"As manifestações espalharam-se pelas cidades do Brasil. Até em Marília houve passeata. Não me pergunte o que está acontecendo. É a vida à beira do abismo. Um abraço." 
Entretanto, ao mesmo tempo em que se mostrava interessado e mesmo atraído pelo tema da "arte de viver à beira do abismo", Manoel estimava necessário construir, erigir algo que protegesse contra o abissal e o que vai junto com ele: a errância, a boemia, a instabilidade, a solidão, a angústia da inundação pulsional. Em suma: conjurar, regular, instituir. Construir um dispositivo de segurança, de homeostase, assegurar um equilíbrio, uma estabilidade; articular, reunir, animar.

Dois nomes-chave portam e conduzem essa tarefa de regulação: instituição (fundar Editora, Laboratório, Associação, a presente Revista) e método (decidir de antemão um protocolo de operações com vistas a um fim, predeterminar o caminho que vai ao objetivo proposto).

Eu me pergunto hoje se o tema da "vida à beira do abismo" não lhe interessava em parte, se não sobretudo, na medida em que ele lhe permitia melhor pensar um dispositivo de segurança contra o abissal, e em particular uma técnica, um último expediente ou recurso face a uma situação potencialmente inquietante, em uma palavra: um método. Um método clínico, certamente, mas também um método geral, uma regula vitce.

No dia 15 de setembro de 2011, Manoel me convidou para dar um 378 seminário em torno da "Vida à beira do abismo: considerações sobre a condição amorosa", na ocasião da comemoração dos 35 anos do Programa de Pós-Graduação em Psicologia Clínica da PUC de São Paulo. Após o debate, quando descíamos juntos a escadaria da PUC, ele me confiou que havia empreendido um estudo sobre Vinícius de Moraes e a vida à beira do abismo, através dos poemas, canções e biografia do poeta da Balada do Mangue, mas que acabou finalmente recuando diante do poço sombrio e sem fundo que vislumbrou: "Muita angústia", me disse.

Parecia-me obscuramente haver aí um ponto de diferença entre nós, mais ou menos implícito, destinado a permanecer tácito.

Conheci Manoel quando entrei na faculdade, no IFCH, em meados dos anos 1970. Ele era o diretor do Instituto. Barba à la Soljenítsin, terno e gravata, carro oficial com chofer pessoal. Para o adolescente que eu era então, vivendo um período de revolta e de militância radical, sob a ditadura militar, ele aparecia como o representante típico da ordem instituída, arvorando os signos da administração, da autoridade e do poder. Durante dois ou três anos eu militei e fomentei a revolta no Instituto e na Universidade o quanto pude, junto com outros estudantes e professores (mais professores do que estudantes). 


\section{EDITORIAL}

Todavia, a reação do Manoel não era a esperada. Ele queria manifestamente entender, escutar, dialogar. Chamou-me várias vezes para conversarmos. Em seguida tomou o hábito, após o expediente, de passar na minha kitchenette de estudante para irmos jantar e continuar a discussão. Em suma, ele me fez pouco a pouco compreender que ele não estava exatamente lá onde o jovem insurgente acreditava situá-lo.

(Mais tarde eu ficaria sabendo, por terceiros, que ele interveio em várias ocasiões para livrar pessoas dos porões da tortura militar. Nos vinte anos de ditadura militar, em 1984, quando ele já estava engajado na sua virada, pesquisando sobre "A noção de sujeito em psicanálise", ele publicaria um estudo inesperado, e esquecido hoje, em torno da cultura popular, precisamente, e da radicalização política: O Centro Popular de Cultura da UNE. É interessante anotar que esse estudo político-cultural de Manoel, concomitante ao começo de sua pesquisa em psicanálise, tem um tema e um objeto bibliográfico em comum com esta pesquisa: o da constituição do sujeito, determinado em seu núcleo como sujeito do desejo.)

O ponto conjeturado de diferença entre nós se situaria no avesso do problema da "arte de viver à beira do abismo". Ele concerneria à questão geral da instituição e da relação ao institucional. Um dos lugares dessa diferença, chamar-se-ia infância; a menos que esse tenha sido o nome de um simples mal-entendido.

Manoel, tal como eu o compreendia, considerava a "infância" uma época da vida, e defendia consequentemente a ideia de que essa época deve ser ultrapassada pelo indivíduo a fim de aceder à maturidade, à vida adulta e autônoma. Eu alegava uma outra ideia de "infância", não como período da vida, mas como condição constitutiva do humano: o nome de sua impreparação nativa, consubstancial e irredutível. O que fazia com que nas discussões que tínhamos, na PUC, na sala da rua Tupi ou andando pelas ruas das Perdizes, ou através do Vale do Anhangabaú no centro de São Paulo (Manoel era um grande peripatético), nossas referências teóricas invariavelmente se invertiam: ele invocava a filosofia clássica da autonomia (aristotélica, cartesiana, kantiana); eu reivindicava o pensamento psicanalítico da heteronomia (teoria do desamparo primordial e do "infantil” em nós).

Ora a infância, neste segundo sentido, é justamente isto que, em cada um, resiste à instituição (criticando-a, burlando-a ou simplesmente suportando-a de modo doloroso...). Inclusive, e eminentemente, em matéria de amor, de paixão amorosa. "Só há amor na medida em que os adultos se aceitam 
infans", escreve Lyotard. Se algo como uma "arte de viver à beira do abismo" se faz necessário, é justamente porque procuramos acolher a infantia que, em nós, espera e às vezes desespera de encontrar uma expressão, para lá dos tipos de frase e gêneros de discurso em vigor (instituídos). E não existe um método para encontrar a expressão justa. A sua busca é o desafio por excelência da arte, da literatura, do pensamento (mas, nós veremos, Manoel concordará com esta última observação).

De qualquer forma, para Manoel, havia um ponto do qual ele nunca abriria mão, como se ele concernisse à sua razão de ser: o da necessidade de construir algo que permaneça, que perdure, que resista ao tempo, e em primeiro lugar ao fim do seu tempo: transmitir um trabalho, deixar um legado, para lá da morte e do esquecimento. Uma espécie de ponte por cima do abismo.

Sabemos que segundo Manoel, depois de uma trentena de anos, a relíquia a legar chamava-se "psicopatologia fundamental".

Sociólogo de formação, Manoel voltou-se para a psicanálise nos anos 1980, na época em que as pesquisas universitárias inter e trans-disciplinares em psicopatologia estavam em plena efervescência na França. Manoel esteve próximo dos psicanalistas franceses que participaram dessa aventura, na esteira da unidade de formação e de pesquisa Sciences Humaines Cliniques de Jean Laplanche (Pierre Fédida, Roland Gori etc.). Desde então ele fez do projeto da "psicopatologia fundamental" o seu cavalo de batalha, até o fim.

Admirável conversão, reviravolta de si, às vésperas da cinquentena. Plínio Dentzien, cientista político do IFCH no período em que Manoel foi diretor (1972-1976), me dizia em setembro de 2010: “A minha opinião sobre o Manoel foi mais que superada quando ele se 'puxou pelos próprios cabelos' e mudou inteiramente a sua vida. Conheço poucas pessoas capazes disso...”.

(O acaso quis que, no momento em que escrevo estas linhas, eu seja surpreendido pela notícia da morte de Plínio Dentzien, professor e amigo querido, cúmplice de várias batalhas "estudantis". Que me seja permitido datar aqui também esta tristeza.

Antes de se formar em direito, depois em ciência política e se especializar na Universidade de Michigan, Plínio foi líder estudantil da União Nacional dos Estudantes (UNE) no Rio Grande do Sul nos anos 1960 - UNE que acolheu a criação do Centro Popular de Cultura (1961-1964), que seria mais tarde o objeto do estudo de Manoel Berlinck, já mencionado. De uma alegria exuberante, Plínio cultivava um gosto do paradoxo e era incomparável na arte 


\section{EDITORIAL}

de conversar. Analista político perspicaz, ele amava a literatura. Conhecedor de Julio Cortázar, se empolgava em imaginar o que teria acontecido se Marx tivesse lido Hölderlin e Hölderlin, Marx. Plínio era um homem generoso e afetuoso. Numa das últimas vezes que nos vimos, ele me surpreendeu com um presente, um exemplar antigo de um livro pelo qual ele exprimia um entusiasmo sem limites: A Morte e a Morte de Quincas Berro d'Água.)

Onde reside o valor de relíquia da "psicopatologia fundamental"?

A concepção de Manoel se situa na trilha de Fédida e dos franceses. Nela o campo balizado pelo nome "psicopatologia fundamental" designa uma prática e um método clínicos, mas sobretudo, e ao mesmo tempo, um campo de pesquisas universitárias transdisciplinares. Há aí uma ideia preciosa: a de articular a "psicopatologia fundamental" com a Universidade, o ensino e a pesquisa, no contexto brasileiro. O objetivo é o de sempre: elevar a qualidade, tanto a do método clínico como a da pesquisa e do ensino universitários.

A ideia é tanto mais preciosa que o ensino em geral na Universidade, e o ensino da psicanálise em particular, encontra-se hoje mais ameaçado do que nunca, nestes tempos de Universidade-empresa mundializada.

Freud já havia levantado a questão num artigo de 1919: "Deve-se ensinar a psicanálise na Universidade?". O projeto de Manoel, quanto a ele, se inscreve na linha direta do programa Psychanalyse à l'Université que Jean Laplanche e Jacques Lacan impulsionaram na França, cada um à sua maneira, sob o élan do movimento de 1968. A história do conceito de psicopatologia fundamental, cunhado por Fédida, é indissociável dessa experiência universitária (ou, de certo ponto de vista, mais próximo de Lacan: "antiuniversitária").

Ligados à orientação "psicanálise na Universidade", convém mencionar pelo menos dois outros traços característicos da psicopatologia fundamental.

O primeiro é o projeto de reestruturar o campo da psicopatologia, tomando em consideração os avanços teóricos e científicos contemporâneos e a multiplicação das abordagens (fenomenologia clínica, biotecnologias e bioética, o problema da transmissão e da herança psíquicas, a procriação tecnomedicalmente assistida, a tecnodependência etc.). Ele visa, assim, identificar modelos e objetos conceituais que ultrapassam as fronteiras disciplinares estabelecidas. Tal é a "fundamentalidade" reivindicada pelo projeto psicopatológico. Ele se propõe a orientar a reflexão transdisciplinar em ciências humanas, em ciências sociais e em ciências da vida.

O segundo traço é decisivo: ele confere a primazia absoluta à psicanálise no projeto da psicopatologia fundamental. A técnica e o pensamento 
psicanalíticos (que Foucault chamou de "saber de espiritualidade", em alusão à grande tradição histórica da cura sui) restam a referência fundadora, originária, condição sine qua non para ser capaz de pensar e dialogar com os avanços teóricos e científicos de nosso tempo. A psicopatologia fundamental é essencialmente uma psicopatologia psicanalítica.

Esses três pontos — psicanálise na Universidade, reflexão transdisciplinar e primado da prática e do pensamento psicanalíticos - circunscrevem o valor da relíquia de Manoel. Ela caracteriza o que Fédida, por seu lado, em 2002, ano de sua morte, chamava de "o tesouro que nós possuímos". Esse tesouro é ipso facto, escrevia ele, "muito invejado pelas ciências neurocognitivas". Ora, "embora a referência às neurociências seja extremamente importante hoje, ela não poderia suprir os modelos teóricos provenientes da psicanálise".

Se indica assim, aqui, o potencial da relíquia: mais do que atiçar a rivalidade entre campos do saber, ele tem um alcance ético, e mesmo político, de resistência aos riscos de invasão e de hegemonia que representam hoje as teorias comportamentais e as neurociências cognitivas. Sem falar do mal por excelência nestes tempos neoliberais: a política de gestão dos recursos 302 humanos e sua palavra de ordem, a avaliação, estendendo-se doravante a todos os domínios, incluindo o campo da saúde mental e das profissões "psi”, até a intimidade mais secreta dos indivíduos.

Ainda e sempre, o que está em jogo é a questão do sujeito. Não o sujeito princípio de homeostase, nem o "sujeito histórico", mas o sujeito elidido ou barrado, instância atravessada constitutivamente por um excesso que, nela, é estrangeiro a ela e vai para além dela. Manoel chamava esse excesso: pathos psíquico; ele pode ir do sofrimento ao entusiasmo, nos levar à patologia, mas também à paixão amorosa e à criação, inclusive teórica. Nós tocamos aqui no coração da relíquia. É o seu destino que está em questão nestes tempos de liberalismo cognitivo e de "vida administrada".

Num mail de 6 de junho de 2009, intitulado justamente "O Método Clínico", Manoel me escrevia: "A pressão... para a internacionalização da produção brasileira é grande. No âmbito da psicologia/psiquiatria/psicopatologia, o único grupo internacional é a Associação [Associação Universitária de Pesquisa em Psicopatologia Fundamental] e batalho para que ela continue assim". Porém, há órgãos brasileiros de fomento à pesquisa que "entendem internacionalização como sinônimo de americanização e isso complica tudo. Há pressão para que sejamos empíricos, quantitativos e imbecis. O Colóquio sobre o Método Clínico é uma iniciativa que visa afirmar a natureza científica 
não americana tanto da psiquiatria quanto da psicologia e da psicanálise. Esse pessoal ... é tão tacanho e caipira que não percebe o que ocorre no mundo. A crise econômica é um claro e definitivo sinal de que o mundo deixa de ser dominado pelos EUA".

Nos últimos anos Manoel conviveu manifestamente mais de perto com a morte, à beira de certo abismo. Os que fazem parte da mailing list da Associação se lembrarão de seus e-mails denominados "boletins de saúde", quando de sua hospitalização no meio de julho de 2013. No dia 27 ele escrevia: "Prezadas e prezados, Lamento informar que passo por um momento difícil. Estou internado no Hospital Samaritano há 13 dias...".

Todos se lembrarão em particular do e-mail, breve mas contundente, do dia 17 de setembro, sobre o inferno hospitalar: verdadeiro diário de viagem ao centro do mundo desumano das condições hospitalares, feitas de incompetência, de indiferença, de maus-tratos e de banalização cotidiana do sofrimento (e concernindo, no caso, a um dos mais reputados hospitais de São Paulo...). Estamos tão longe assim das páginas terríveis da autobiografia de um Thomas Bernhard, entregue aos médicos imbuídos de uma concepção comercial da medicina?

Em todo caso, para Bernhard, o que salva nessa situação de profundo desamparo, é "tomar-se a si próprio em mãos"; para ele isso equivale a escrever, para Manoel, "pesquisar". O seu e-mail é um pequeno relato de pesquisa, forte, revoltado e não desprovido de humor.

No texto "Envelhescência", de 1996, a dimensão pessoal, autobiográfica, é manifesta, autorretrato incluído. Ele já evocava a condição do sujeito "envelhescente", confrontado ao reconhecimento de sua solidão fundamental. O sujeito "se descobre mais sozinho do que nunca, ainda que possa estar rodeado de um grande número de pessoas com quem interage cotidianamente." A "envelhescência" é o nome dessa condição que exige uma arte específica de viver à beira do abismo "onde o humano se encontra em sua mais completa solidão"; arte que "requer muito engenho e muito empenho", incluindo uma "solicitação à estética do corpo". "Na envelhescência [o sujeito] se surpreende pensando na proximidade da morte, a inseparável companheira da vida. Os projetos já não podem ser pensados a longo prazo, pois este se reduz a dez ou vinte anos, no máximo." Seriam vinte anos.

No e-mail de 27 de janeiro de 2013, de volta das férias no Rio, Manoel evoca os "homens cariocas... alucinados com as meninas lindas... que por sua vez, são muito espertas e suportam bem o assédio, cuidando para ficarem 
cada vez mais lindas". "Eu, nessas horas, confidencia ele, aproveito para ficar recolhido, ler e refletir sobre a vida." Comentei-lhe, em retorno, que no seu relato ele aparecia "ao mesmo tempo dentro e fora do burburinho das excitações cotidianas, o que dá ao relato um tom de paz-com-o-mundo — invejável, justamente".

Ele me respondeu no mesmo dia: "Querido Plínio, Você captou perfeitamente meu estado de espírito: uma certa serenidade diante da proximidade da morte. Fiz 76 anos e parece que a angústia arrefeceu. Mas, desconfio disso. Afinal, essas paixões são incontroláveis, como bem sabemos. A velhice impõe cautela. A minha acelera os sonhos. O corpo impõe uma coreografia lenta. Mas os sonhos são bem agitados. Por isso, o mundo torna-se um pouco mais distante... A agitação do mundo faz parte dele e não de mim. Estou nele, mas não sou dele. Assim, voltei a escutar música, a ler ficção e não perder a paciência facilmente. Os cuidados da A. C. são muito importantes para que eu possa suportar esses últimos rounds. Entretanto, não posso descuidar da gestão... Porém, como você sabe muito bem, o Brasil só entra no ritmo depois do carnaval".

Manifestamente a partir de 2013 Manoel sabia que ia morrer, num prazo mais ou menos curto, questão de alguns anos. Foram três e meio.

Eu imagino então que, à irreverência dele somou-se uma espécie de revolta face ao declínio inelutável, à solidão inexorável, a angústia de quem vive. A supor que a vida seja mulher, Manoel amava uma como se ama a outra (ainda Vinícius de Moraes).

Quando Vinícius, após uma noite de sonho premonitório, fica sabendo, de manhã, que Mário de Andrade acabara de morrer, ele escreve um poema, "A manhã do morto" (1945). No poema Mário o acompanha, a seu lado ao longo de todo o dia, o dia seguinte de sua morte. Espantado, admirado com a vida, que ele vê por assim dizer do exterior, de além-túmulo, o morto se exclama então para Vinícius: “Que maravilha é viver!”. Declaração absoluta de amor à vida.

Manoel sem dúvida a coassinaria, com Mário e com Vinícius. Convém lembrar que Vinícius retomará a frase, dez anos depois, numa canção de amor. "Se todos fossem iguais a você". Que maravilha é viver quando se ama mesmo se é à beira do abismo.

Mais uma vez: amar e ser amado.

Em novembro de 2015 fui dar duas palestras na Universidade Federal do Rio de Janeiro e passei por São Paulo. Telefonei para Manoel para marcarmos 


\section{EDITORIAL}

um almoço; ele propôs o dia 18 de dezembro. Almoçamos num restaurante de carnes na rua Tupi; ele abriu uma exceção ao seu regime de sobriedade e nós tomamos vinho.

Colocamos nossa conversa em dia, como ele gostava de dizer. A crise política brasileira; o desmantelamento da esquerda no Brasil e na França; a ofensiva jihadista planetária e seu novo alvo, a Universidade; o próximo Congresso Internacional de João Pessoa sobre a qualidade. Na hora de eu ir embora, Manoel me acompanhou na busca de um táxi. Nos despedimos, ele ficou me olhando meditativo. Quando eu já estava dentro do táxi, Manoel, como interpelado por algum pensamento, virou-se da calçada, como se quisesse me dizer algo, o táxi esperou, mas ele desistiu. Foi a última vez.

Eu só retive a data de nosso encontro porque Manoel divulgou na mailing list da Associação, no e-mail desolado do 20 de janeiro de 2016, intitulado "Atentado à Universidade", a conversa que nós havíamos tido sobre o jihadismo, precisando a data: "Prezadas e prezados, Em conversa com Plínio Prado, ocorrida no dia 18 de dezembro de 2015, ele previu o que ocorreu agora. Um ataque terrorista a uma Universidade. Foi no Paquistão. Mas poderia ser em qualquer outra. A Universidade é inimiga do terrorismo, pois é o que melhor representa a civilização ocidental. Outros atentados a Universidade ocorrerão. Estou desolado. Um abraço".

Somente após a sua morte é que fiquei sabendo que 18 de dezembro era o dia de seu aniversário.

Num artigo intitulado "Autoria", Manoel, se insurgindo contra as normas científicas e universitárias da dita objetividade, anônima e impessoal, defende a inscrição da subjetividade do "autor" no texto que este escreve. O artigo é curiosamente assinado: "Manoel Tosta Berlinck e Mário de Andrade". Ele foi enviado à lista da Associação no primeiro dia de janeiro de 2013, de manhã. O seguinte comentário o acompanhava: "Prezadas e prezados, Preparei um artigo com Mário de Andrade para presenteá-lo de Ano Novo".

Mário de Andrade não é citado no texto; ele só o "assina". Em compensação, ele é citado num outro texto, a propósito do mesmo assunto; o que esclarece a meu ver essa referência, o enigma dessa coassinatura e o presente de Ano Novo. Trata-se de "Transmissão e laço social da psicanálise do Brasil", texto escrito 24 anos antes (1989), que fecha o volume Psicopatologia fundamental. Afirmando que "a heterodoxia requerida para a escuta do inconsciente é da ordem da poiesis, ou seja, da criação artística", 
ele convoca o artigo "O artista e o artesão" de Mário de Andrade, para parafraseá-lo: "a psicanálise como a arte, na realidade, não se aprende". Pode-se aprender, evidentemente, o elemento técnico, "mas o domínio da técnica é insuficiente para que um psicanalista se constitua como tal".

Algo aqui excede o método. Poderíamos dizer: não se aprende a psicanálise, aprende-se somente a psicanalisar. (É exatamente o que diz Kant da filosofia.) Há uma dimensão de arte, arte de escutar, arte de ler, de interpretar, arte de escrever, que é inensinável. A essa arte, só se pode buscar acesso por si próprio, mediante um trabalho de si sobre si (e contra si).

À luz da maravilha de viver, da angústia e da revolta contra a morte, da preocupação em deixar um legado, e de amar e ser amado, há uma frase forte e crua de Mário de Andrade que poderia, por sua vez, ser coassinada por Manoel Berlinck, tanto ela tem o rosto dele. Ela diz o seguinte: "Sou bastante artista, pelo menos até o ponto de desejar essa besteira inacreditável e inexplicável de continuar querido depois de cadáver, osso, pó filho da puta".

Uma vez mais, amar e ser amado, amar ser amado. Mesmo depois de morto, corpo em decomposição.

Sabe-se que o amor é uma ponte que nos mantêm ligados aos que se foram, nós os vivos, sobreviventes; enquanto eles forem amados, viverão. Disso, a relíquia de Manoel, o legado, deveria ser uma garantia.

A longa história da cura sui e de suas transformações, talking cure incluída, nos ensina que um indivíduo vem a si, engaja uma relação de si consigo mesmo, através da relação com um outro, que o escuta, em quem ele confia e que confia nele.

Manoel tinha esse talento de despertar as pessoas para elas mesmas, de fazê-las acreditar nelas mesmas, em suas potencialidades, descobrir suas possibilidades. Os amigos pessoenses, no último Congresso Internacional de setembro de 2016, testemunharam isso com uma força, uma veracidade e uma delicadeza imensas.

Ele fez uma diferença na vida dos outros, dos que o encontraram. Ele os encorajou a se transformar em si mesmos, a mudar sua vida, como ele mesmo mudou a sua, a seguir a sua própria via (desligando-se consequentemente do professor ou do analista, indutor ou iniciador), a procurar vir a ser o que eles devem ser. E isso — para lá das instituições — nada poderá apagar. 


\section{EDITORIAL}

Citação/Citation: Prado, P. (2016, setembro). Editorial. Ao Manoel Berlinck que eu conheci. Revista Latinoamericana de Psicopatologia Fundamental, 19(3), 373-387.

Editores do artigo/Editors: Prof. Dr. Manoel Tosta Berlinck e Profa. Dra. Sonia Leite

Recebido/Received: 20.10.2016/ 10.20.2016 Aceito/Accepted: 23.10.2016 / 10.23.2016

Copyright: (C) 2009 Associação Universitária de Pesquisa em Psicopatologia Fundamental/ University Association for Research in Fundamental Psychopathology. Este é um artigo de livre acesso, que permite uso irrestrito, distribuição e reprodução em qualquer meio, desde que o autor e a fonte sejam citados / This is an open-access article, which permits unrestricted use, distribution, and reproduction in any medium, provided the original authors and sources are credited.

\section{Plinio Prado}

Université de Paris VIII, Département de Philosophie.

2, rue de la Liberté

93526 Saint-Denis, France

plinio.prado@univ-paris8.fr

Website de PW Prado Jr.

http://www.atelier-philosophie.org

This is an open-access article, which permits unrestricted use, distribution, (cc) BY-NC and reproduction in any medium for non-commercial purposes provided the original authors and sources are credited. 